the adductor pollicis and flexor brevis minimi digiti muscles to the long peroneal tendon, this prolongation of the tibialis posticus gives off two diverticula, which pass for insertion to the bases of the second and third metatarsal bones.]

And, lastly, with regard to the other proposition-whether the long plantar ligament or fascia possesses in itself such an amount of contractile power combined with elasticity as to admit of its yielding sufficiently to deaden or counteract shock, and subsequently to resume the requisite amount of solidity or rigidity to enable it to maintain the integrity of the arch, we obtain a reply in the negative from the arrangement of parts, which shows that, after all, the influence exerted by this fascia over the longitudinal arch is passive and mediate, and neither active nor direct; indeed, it is very questionable whether its fibres are ever stretched, or even extended, under pressure or shock, since especial care is taken to prevent their being so. The ligament does not pass straight across from point to point, but describes a curve the concavity of which looks downwards-corresponding, in fact, to the plantar arch; and this curve is preserved in the various positions of the foot by a very ingenious contrivance, and upon which the elasticity and at the same time firmness which is the perfection of walking mainly depends. The three muscles constituting the first layer of the muscles of the sole of the foot-the abductor pollicis, flexor brevis pedis, and abductor minimi digiti, which serve, as we have seen, to fix the anterior pillar of the arch when the latter is subjected to pressure, have a very peculiar origin. They arise from bone-the inferior surface of the os calcis-by their upper surfaces, and from the long plantar ligament by their lower. This arrangement not only adds strength to the muscles by increasing their extent of attachment, but, through it, the muscles, when called into action, cannot exert their influence from before backwards upon the anterior pillar of the arch witbout at the same time acting from below upwards upon the plantar fascia, whereby its strength and tensity, and at the same time its relation to the bony arch, are effectually preserved where otherwise they would be destroyed. The result of this arrangement is well seen in the foot of the dancer when moving about on the tips of the toes. Here the arch is not destroyed, but, on the contrary, is usually exaggerated-due, no doubt, to the great force which these muscles have to exert during this particular movement acting not only upon the anterior pillar of the arch, but at the same time upon the plantar fascia.

\section{A CASE IN WHICH TYPHOID FEVER AND MEASLES WERE COINCTDENT.}

BY W. B. KESTEVEN, F.R.C.S.

ON the 14th, 15th, and 16th of last December, a girl, aged fourteen years, was ill with measles. A few days afterward another girl, aged eleven years, was indisposed, and suffering from symptoms of fever of the enteric type. On or about the 30 th of December, a few of the rose-coloured spots characteristic of typhoid fever made their appearance, and increased in number, but did not exceed thirty or forty over the whole of the trunk. On the 8th of January, two younger children presented the ordinary symptoms and eruption of measles, and passed through the disease in the usual course.

On the 8 th of January I was considerably puzzled by finding my typhoid patient exhibit the general symptoms and special rash of measles in addition to that of the enteric fever. I began to doubt the correctness of my diagnosis as to either the one or the other of the two diseases, and was, therefore, only too glad to avail myself of the superior judgment and greater experience of Dr. Jenner, who, after careful investigation into the history and condition of the patient, confirmed my opinion that I had here a case in which these two eruptive fevers were coincident. At the same time my doubts were more than justified by Dr. Jenner's statement that he had only once before met with such an occurrence. The rarity of such coincidences is, therefore, obvious ; but their occasional occurrence has been recorded. Thus Mr. Broke Gallwey published in THE LANCET of the 28th of August, 1858, a case of Small-pox supervening on Measles, and another on Scarlatina. In the Journal of Public Health for October, 1856, is published a paper of my own, read to the Epidemiological Society, and in which I described a series of cases wherein measles and scarlatina were concurrent. Doubtless other instances of the same kind have happened; but I have notes only of the above.

It may not be uninteresting, with reference to etiology in the above case, to add that exactly opposite the house in which it occurred there is one of the ventilation gratings of the street sewer. I do not doubt that these openings have much to do with the spread of typhoid fever in the suburbs of London. I have been in practice in this place nearly thirty years, and for upwards of twenty years of that period I never met with a case of typhoid fever. Since the new sewers have been made the cases have become very numerous. Doubtless it would be a great benefit to do away with cesspools in crowded districts but it is doubtful whether, as at present constructed, without ventilation shafts, the sewers are anything better than elongated cesspools, diffusing through their air-gratings the causes or abettors of various forms of disease.

Holloway, June, 1866.

\section{CASE OF}

LONG RETENTION OF FOREIGN BODIES IN THE INTESTINES WITHOUT SERIOUS SYMPTOMS RESULTING.

By EDWARD W. H. PILCHER, Esq., M.R.C.S., RESIDENT MEDICAL OFEICER TO THE PECKHAM HOUSE ASYLCM.

M. B- was admitted into the asylum on the 5th of December, 1862. The patient was described as being forty years of age, but she had the appearance of being over fifty. She was of tall stature; spare habit of body; anæmic complexion; head of moderately good conformation; eyes lighthazel; pupils very willely dilated, but regularly so, and fairly and equally sensitive to light; tongne furred; pulse regular, soft, and very compressible; skin hot and dry; respiration normal; teeth all loose; catamenia absent. She was suffering from acute melancholia; refused food, but would assign no reason for so doing; very taciturn. She continued in about the same state-sometimes better and taking her food, and then again relapsing-till January, 1864, when she had a very sharp attack of rheumatic fever, from the effects of which she was some time recovering. At the latter end of August, 1864, it was discovered that she had been swallowing foreign substances, with a view to self-destruction. The only information to be gained from the patient herself was that she had swallowed some garden nails used in training the rose trees \&c. against the wall of the airing court; and that, as they seemed to stick in her throat, she had swallowed stones to force them down. She was immediately put to bed, with the view of preventing her from swallowing more things, and that she herself and the evacuations might be steadily watched. A small dose of castor oil was also administered. The next day she began to pass per anum one or two pieces of broken crockeryware of a triangular shape, having a base from half an inch to an inch, and from half an inch to one inch and a quarter in altitude, together with pieces of glass of about the same shape and size, and one or two garden nails and one stone. There were severe enteritic pains, which were relieved by sinapisms over the abdomen, and large linseed-meal poultices on their removal. These pains occurred at intervals during the whole time the foreign bodies were passing, extending over a period. of ten weeks, and were always relieved by the same remedy, and small doses of castor oil occasionally. During this period she took passively everything that was given her, and improved. in bodily health and appearance, had more colour, and grew fatter (probably from the effect of the iron that was being gradually absorbed). The total amount passed that was found weighed ten ounces, and consisted of nineteen sharp garden nails, one $2 \frac{1}{2}$-inch screw, pieces of broken crockeryware and glass, one needle (broken), two pins, whalebone, \&c. Shortly after she ceased to pass any foreign substance she again refused food, fell away in flesh, although extra diet and tonics were civen her, and for the past six months she has been kept alive by food given her twice or thrice daily by the stomachpump. She never speaks, but lies in bed or sits in an easychair without motion, taking no notice of anything that is going on around her.

The peculiarity of this case consists, perhaps, not in the fact that the foreign bodies were swallowed-which is not very uncommon in cases of melancholic mania, - but that they should have remained for so long a period (ten weeks) in the 
intestines without producing more serious symptoms. That $\mid$ of Wunderlich's observations, our readers will remember, show only one stone was found I attribute to the fact that, being taken from water-worn gravel, they were more or less round, and so produced less intestinal disturbance, and had passed more rapily through the bowels than the angular pieces.

Peckham, June, 1866.

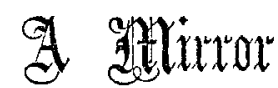

OF THE PRACTICE OF

\section{MEDTCINE AND SURGERY IN THE}

HOSPITALS OF LONDON.

Tulla autem est alia pro certo noseendi via, nisi quamplurimas et morborum et dissectionum historias, tum aliorum, tum proprias collectas habere, et int se comparare.-MIorgagri De Sed. et Caus. NHorb., lib. iv. Procemium.

\section{ST. GEORGE'S HOSPITAL.}

RENAL DROPSY; TYPHOID FEVER; SCARLET FEVER; ACUTE NEPHRITIS; DEATH.

(Under the care of Dr. BAfClAF.)

Nerther the typhoid fever in the following case nor the scarlatina which, by a curious complication, supervened, was severe in character. The fatal result was evidently due to acute nephritis attacking kidneys already disorganized by previous disease. The chart of thermometrical observations, for which, as well as for notes of the case, we are indebted to Dr. Peginald Thompson, medical registrar, shows very clearly the sudden rise in temperature which marked the occurrence of scarlatina as well as the characteristic fluctuations during the progress of typhoid symptoms. Owing to the patient not having been admitted until the tenth day of the disease, the observations of the temperature only commence at that date. The results a remarkable regularity in the thermometrical ranges at the onset of the disease, which may be thus briefly summarized:lst day: Morning, 98.5 ; evening, 100.5'. 2nd day: Morn. ing, $99 \cdot 5^{\circ}$; evening, $101 \cdot 5^{\circ}$. 3rd day: Morning, $100^{\circ} 5^{\circ}$; evening, $102 \cdot 5^{\circ}$. 4th day: Morning, 101.5\%; evening, $104^{\circ}$. On the third or fourth day the height of the fever is attained when the temperature in the evening amounts at least to $103.5^{\circ}$. From that time onwards the fever proceeds in regular stages of weekly and half-weekly periods. The figures of the successive temperatures may not follow exactly the standard we have given, but they will always conform, with greater or less exactness, to this order of succession; and, in particular, the remarkable changes which regularly occur between evening and morning are highly characteristic of typhoid fever. The zigzag line in the accompanying chart marks their occurrence between the tenth and twentieth days.

Roger $\mathrm{P}$-, aged twenty-two, was admitted in December, 1865, with dropsy and alluuminuria of nine months' date, and was sent out in the course of the following month much im. proved in general health, the dropsy having subsided. $\mathrm{He}$ was readmitted in March, 1866, with the usual symptoms of typhoid fever. The history was that he had been seized ten days before with shiverings, headache, and loss of appetite; followed in two days by vomiting, and in four days by diarrhoea of a severe nature.

On admission he was very pale; the legs were slightly odematous ; there were a few rose-coloured spots on the belly but no pain or tenderness. Tongue very large and red, with a dirty fur and a tendency to ulceration at the edge. The urine was full of albumen with some blood, very dark-coloured, scanty, and muddy; specific gravity 1020. For three days after admission fresh crops of rose-coloured spots made their appearance, but no very severe diarrhœa occurred while he was in the hospital; and during the third week of the fever he was making very good progress towards recovery. This was indicated by the thermometer, as will be seen from the accompanying chart, from the sixteenth to the twentieth day: the pulse during these days varying from 88 to 92 beats in the minute; the urine being increased in quantity, and clear, but albuminous.

In the following chart the observations made at ten A.M. and six P.M. are recorded in degrees of the Fahrenheit scale.

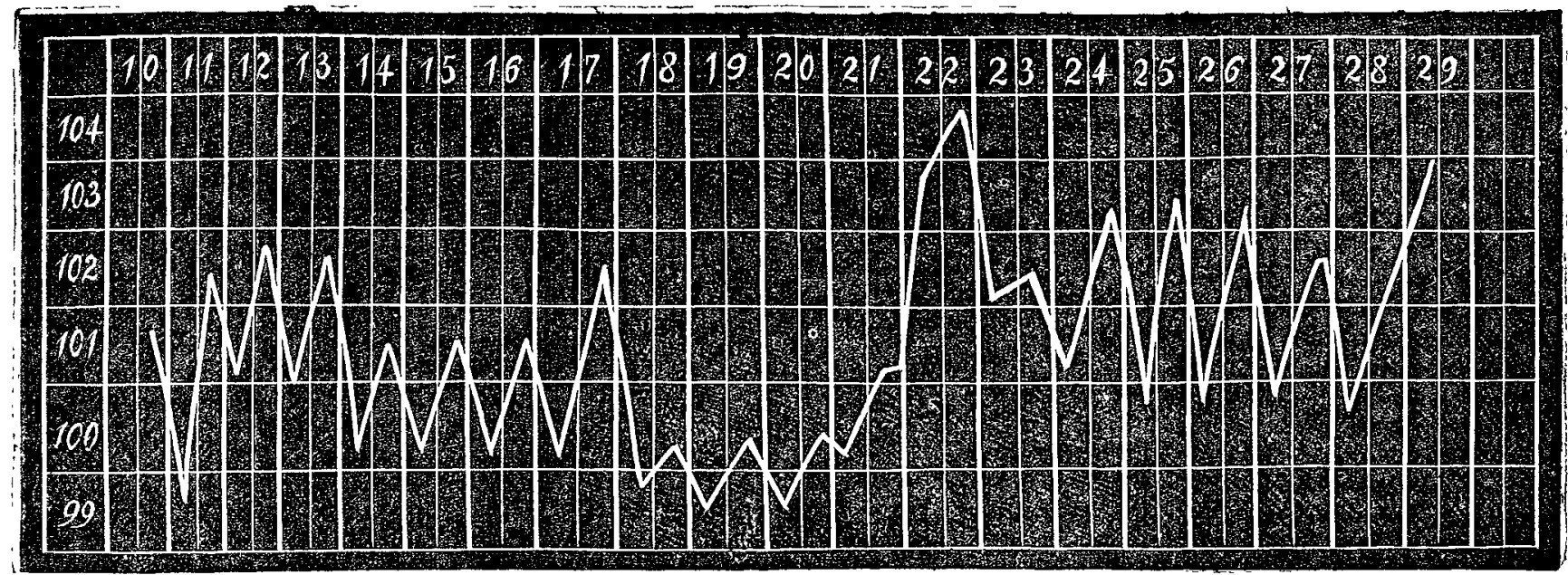

On the twenty-first day of illness he began to complain of fresh symptoms. He was uneasy; had rigors, and was much flushed; suffered from pain and heat in the stomach; and the urine was diminished in quantity. From the chart it will be seen that the thermometer indicated a rise in temperature, which was very much increased on the following day. The nulse-rate rose from 96 on the twenty-first day to 120 on the trenty-second.

As to the nature of the complication from which the patient was suffering, the thermometer indicated that it was either scarlet fever or erysipelas; it eventually proved to be the former. In the evening of the twenty-second day the rash of scarlet fever made its appearance, and sore-throat was complained of on the following day. The rash was slight, and faded on the twenty-sixth day; but on the twenty-seventh day he was evidently not so well; was very heavy; the pulse was rapid ; and the urine much diminished in quantity. The total amount of the urine passed daring the twenty-four hours was therefore collected, and found only to amount to for ounces; it was full of albumen, and contained some transparent casts of extraordinary dimensions, with renal epithelium and pus in large quantities. On the twenty-ninth day the breathing was extremely rapid, 52 in the minute. He complained of pain in the right side and stomach, was livid and delirious, and was evilently dying. A senna injection was at once administered, and he was dry-cupped over the loins; but he never rallied, and died in the afternoon of the twenty-ninth day of illness.

The following notes of the autopsy are taken from $\mathrm{Mr}$. Whipham's record in the post-mortem register.

The right pleural cavity was full of thin bloody fluid, the lung being quite collapsed. The kidneys were very large, weighing twenty ounces; the capsules were thickened, and slightly adherent. The surface was smooth, pale, and mottled. A section under the microscope showed the uriniferous tubes quite choked with epithelium. The small intestines were congested, but no traces of ulceration could be discovered except near the ileo-crecal valve, where one or two small patches, thickened and raised above the mucous membrane, were found. 